\title{
DIARY BOOK MEDIA FOR MONITORING THE TEETH BRUSHING ACTION OF ELEMENTARY SCHOOL
} STUDENTS

\author{
Hermien Nugraheni ${ }^{1)}$, Sadimin ${ }^{2)}$, Endah Aryati ${ }^{3)}$, Raaufa I. Nurjati ${ }^{4)}$, Ismi Rajiani ${ }^{5{ }^{*}}$ \\ 1,2,3,4 The Ministry of Health Polytechnic Semarang, Indonesia \\ ${ }^{5}$ Post Graduate Program of Muhammadiyah University Gresik, Indonesia
}

Article Info: Received 20 October 2019; Accepted 28 November. 2019

DOI: https://doi.org/10.32553/ijmbs.v3i11.783

Corresponding author: Ismi Rajiani

Conflict of interest: No conflict of interest.

\section{Abstract}

Background: Indonesian population who brushed their teeth correctly twice a day is only $2.8 \%$. This shows that education about brushing teeth must start early. The purpose of this study was to determine whether there is an impact of education using diary book media on the correct action of brushing teeth on elementary school students.

Methods: The research design used was quasi-experimental with non- equivalent control group design. Interventions were given to elementary students in one school, and another school was used as a control group. Intervention activities carried out on the students are education using the correct diary or brushing diary. Analysis of the data used is a comparative test with a statistical t-test independent t-test, which aims to find out the average value difference between the group with the intervention and the group that did not get the intervention in the form of a diary media use or rubbing diary tooth

Result: The result is that there are differences in the actions of students who brush their teeth correctly in the group that gets the intervention and those who do not get the educational intervention using the media of the tooth brushing diary book. There is a difference in the correct action of brushing teeth between students before and after getting an educational intervention using a tooth brushing diary book.

Conclusion: School-age children are a time of imagination, creativity, and storytelling. So the diary or diary is very suitable as an educational medium in the effort to change behavior in introducing the way to maintain health of the teeth.

Keyword: Diary Book, Teeth Brushing Action, Students

\section{Introduction}

Data of Indonesian Ministry of Health in 2018, 93\% of early childhood, i.e. in the age range 5-6 years, experience cavities. This figure indicates that only 7 $\%$ of children in Indonesia are free from problems of dental caries. This can affect the nutritional status of children because cavities make children refuse to eat ${ }^{1}$. The cause of cavities in $93 \%$ of Indonesian children can be triggered by various things ranging from milk feeding while sleeping, giving high sugar foods and drinks, to the lack of Parental awareness to teach their children to brush their teeth ${ }^{2}$.

Dental and oral diseases significantly affect the degree of health, the process of growth and development, even the child's future. Children are prone to malnutrition because the pain in the teeth and mouth decreases their appetite ${ }^{3}$. Children's learning ability will also decrease so that it will affect learning achievement. The high number of dental caries and the low status of oral hygiene are dental and oral health problems that are often found in the age group of children. Dental caries can cause difficulty in eating in children because dental caries causes a decrease in the function of teeth as a digestive tool.

The most important thing in maintaining oral and dental hygiene is the awareness and behavior of maintaining oral hygiene. This is so important because its activities are carried out at home without any supervision from anyone, it depends entirely on the knowledge, understanding, awareness, and willingness of the individual to maintain oral health. Behavior is an action or activity that is a response or reaction of an individual to stimulation originating 
from outside or from within himself ${ }^{4}$. Changes in behavior cannot be achieved directly so that educational efforts are needed to influence someone in changing their behavior.

Dental health education is an intervention activity carried out by providing information, invitations, persuasion, persuasion, and awareness to producing behaviors to maintain, maintain or improve good dental health ${ }^{5}$. To obtain valid results, educational aids or media are needed. The function of the media in education is as a visual aid to convey information or messages about health ${ }^{6}$ that media selection must be adjusted to the characteristics of students.

School-age children are a time of imagination, creativity, and storytelling. So it is crucial to practice story and writing skills. Bearing this in mind, diaries or diaries are considered suitable to be used as educational media in behavioral change efforts ${ }^{7}$. Because in the diary there is an element of excitement which is an essential factor to provide student motivation to learn, ${ }^{8}$ students will record their tooth brushing actions and activities at home in a diary to record the type, frequency, duration, tooth brushing techniques and tools and materials used in carrying out these activities. This diary is useful for determining the area of problem in a child's toothbrushing behavior. This self-monitoring can empower children to make them more aware of the pattern of toothbrushing activities ${ }^{9}$.

The purpose of this study is to determine the impact of using diary book media on correct toothbrushing actions in elementary school students in the working area of Kedungmundu Public Health Center in Semarang City 2019.

\section{METHODS}

The research design used was quasi-experimental with non- equivalent control group design. An assessment of caries prevention knowledge and actions with correct tooth brushing actions for elementary students was conducted for elementary students in the working area of the Kedungmundu Health Center in Semarang. Interventions were given to elementary students in one school, and one other school was not given an intervention that was used as a control group. The intervention activity carried out on the students was education using a toothbrush diary book.

Analysis of the data used is a comparative test to compare (differentiate) two variables (data) there are similarities/ differences. The statistical test used was an independent t-test, which aimed to find out the average value difference between the groups with the intervention and the group that did not get the intervention in the form of the use of diary media or tooth brushing diaries.

\section{RESULTS}

Health Center Kedungmundu Semarang is the health center with the highest number of people with dental and mouth pain who need treatment. So that the Kedungmundu Health Center is increasing its efforts in fostering UKGS activities in primary schools in its working area, especially for screening activities that are followed by care and education about correct tooth brushing.

Primary schools in the working area of the Kedungmundu Health Center are 31 SD / MI, both public and private. With the number of class $\mathrm{V}$ students (aged 10-11 years) as many as 623 students. In this study cluster, random sampling found 35 students in the intervention group namely fifth-grade students of Sambiroto 1 elementary school and 35 students in the control group namely fifth-grade students of Sendangmulyo 1.

Table 1: Characteristics of Respondents

\begin{tabular}{llll}
\hline No & Variable & $\begin{array}{l}\text { Intervention } \\
\text { Group }\end{array}$ & $\begin{array}{l}\text { Control } \\
\text { Group }\end{array}$ \\
\hline 1 & Gender: & & \\
& Male & $37 \%$ & $41 \%$ \\
& Female & $63 \%$ & $59 \%$ \\
\hline 2 & Age & & \\
& $10-11$ years & $87 \%$ & $89 \%$ \\
& $<10$ years or $>11$ years & $13 \%$ & $11 \%$ \\
\hline 3 & Parents' Jobs & & \\
& Government & $32 \%$ & $28 \%$ \\
& Employees & $47 \%$ & $45 \%$ \\
& Private Employees & $21 \%$ & $27 \%$ \\
& Self Employed & & \\
\hline
\end{tabular}

From table 1 it appears that respondents, both in the intervention group and the control group, were more female than male, were mostly 10-11 years old, and most of their parents' jobs were private employees.

Based on the results of research on correct tooth brushing actions covering the right time, the right tool and the right way for students in the intervention group and the control group, are as shown in Table 2. 
Table 2: Student Brushing Actions Before and After Intervention

\begin{tabular}{lllll}
\hline No & Category & \multicolumn{2}{l}{ Group Intervention } & Control Group \\
\cline { 3 - 4 } & Action & $\begin{array}{l}\text { Before } \\
(\%)\end{array}$ & $\begin{array}{l}\text { After } \\
(\%)\end{array}$ & \\
\hline 1 & Poor & 29 & 12 & 30 \\
\hline 2 & Moderate & 68 & 85 & 69 \\
\hline 3 & Good & 3 & 3 & 1 \\
\hline \multicolumn{2}{l}{ Total } & 100 & 100 & 100 \\
\hline
\end{tabular}

In the intervention group, students whose tooth brushing actions in the lousy category decreased from $29 \%$ to $12 \%$ after being given an educational intervention using a toothbrush diary media whereas students whose teeth brushing was in the moderate category increased from $68 \%$ to $85 \%$ after being given an educational intervention using a tooth brushing diary media. Meanwhile, most of the students in the control group (69\%) had moderate tooth brushing, and there were still quite a number of them (30\%) whose tooth brushing was included in the bad category.

Before a different test is conducted before and after an intervention, a data normality test is performed to determine whether the data are normally distributed or not. Furthermore, the data normality test results are as shown in Table 3.

Table 3: Data Normality Test

\begin{tabular}{lll}
\hline Intervention & P-Value & Remarks \\
\hline Before & 0.060 & normally distributed \\
\hline After & 0.092 & normally distributed \\
\hline
\end{tabular}

From the processing of data normality test with the one-sample Kolmogorov Smirnov test, Table 3 shows that the significant value of tooth brushing actions students before and after the intervention compared with the value of $\alpha=0.05$ indicates a higher number so that it can be concluded that the data are normally distributed $(p>0.05)$.

Then the data were analyzed by statistical tests using independent t-tests. The calculation results can be seen in Table 4 below.

Table 4: Results of data analysis using the independent t-test

\begin{tabular}{lll}
\hline Intervention & Mean & P-Value \\
\hline Before & 83.42 & 0.000 \\
\cline { 1 - 2 } After & 81.26 & \\
\hline
\end{tabular}

From table 4 it can be seen that the mean value of correct brushing action on students before intervention is 83.42 and after an intervention is 81.26 so that the difference between before and after the intervention can be seen is 2.16 . Moreover, when viewed from the $p$-value of the test difference between the two treatments showed that the $p$-value of 0,000 . This value indicates less than 0.05 , so it can be concluded that there are differences in the correct action of tooth brushing on students between before and after getting educational intervention using the toothbrush diary media.

\section{Discussion}

Efforts to maintain oral health should be made as early as possible so that dental caries can be prevented from happening to children. School is one of the environments that can be used as a place to hold dental health promotion.

Children are one component of society. Children at school age are susceptible to various health problems, such as dental caries, helminthiasis, visual acuity disorders, and nutrition ${ }^{10}$. Therefore, the period of starting school is an important step to develop children's habits to always maintain health from an early age through health education programs. Dental and oral health education is an effort to influence a person to behave well and motivate to maintain oral health, as well as increase public awareness of the importance of oral health and provide an understanding of ways to maintain oral health ${ }^{11}$. Children's oral health and teeth are generally found to be in poor condition with a plaque and other deposits on the surface of the teeth. Plaque collection will cause an increase in carbohydrate fermentation by acidogenic bacteria, which then will cause salivary $\mathrm{pH}$ to fall if salivary $\mathrm{pH}$ drops to a critical threshold, it will cause enamel demineralization which will then lead to dental caries ${ }^{12}$. The cause of caries in children is lack of knowledge about the time to brush teeth and the right way to brush. Children spend most of their time in school, so the development of a healthy environment and the adoption of health-promoting behaviors are appropriate when done in school. School student interventions are carried out with the aim that learning about dental hygiene and health can be carried out as early as possible to increase students' knowledge about the importance of maintaining health, especially dental and oral health as well as general health and the environment ${ }^{13}$. Dental health education in children is an effort that will emotionally eliminate fear, foster curiosity, want to observe, and 
finally physically will carry out activities in such a way that is good for personal health. The purpose and goal of dental and oral health education for children are essential to introduce children to the world of dental health and all issues concerning teeth so that they can maintain dental health, train children's limbs so that they can clean their teeth according to their abilities, and get cooperation. Both children if they need treatment on their teeth. Another opinion states that the purpose of dental and oral health education is to increase the ability of the community to help themselves in the field of health, especially dental and mouth health, can play an active role in supporting health, especially in oral health, changing one's behavior patterns for healthy living, especially those relating to dental and oral health, as well as supporting general health development ${ }^{14}$.

The process of behavior change goes through four stages namely the first function or knowledge function is that individuals have begun to recognize new information and learn to understand new objects, for example when a dentist explains to a patient that the patient can eliminate specific unhealthy symptoms in his mouth, for example by cleaning plaque, because plaque is one of the most important reasons why his mouth is unhealthy, then a patient who does not know will receive treatment. The second function, namely the belief function, means that individuals have formed positive or negative attitudes towards the new information or object. The third function is the determining function in which the individual acts actively which leads to the selection of changes that may or may not be accepted. In this third function, the individual knows far enough that he can make the decision to prevent as much plaque as possible and ask the dentist how to do the best, or may also decide not to do anything because it considers plaque cleaning and oral health not so necessary. The last function is the approval function; here, individuals are willing to carry out new behaviors following health norms. At this stage, the individual seeks further information to complement what has been decided with new impulses and can retract his decision if, for example, receive information that careful cleaning of the plaque is not helpful. Behavioral change has intentional characteristics; some exercises are done intentionally and consciously, positive changes so that as expected, can effectively bring influence and meaning, have direction and purpose, and include all aspects of behavior namely knowledge, attitudes, and skills ${ }^{15}$.

Counseling is a method often used in dental and oral health education. Counseling methods commonly used are the didactic method (one-way method) and the Socratic method (two way-method). In the didactic method, educators tend to be active while students as target educators are not allowed to express their opinions. The lecture is one of the right didactic methods used in dental and oral health education for elementary school children. The purpose of this method is to provide as much knowledge as possible. The advantage is that it can be accepted by students who do not want to read; it is easy, and cheap. The disadvantage is that it does not allow the listener to participate and the feedback is less known because the idea only comes from one person. The method is done by two-way communication between students and educators. Students are allowed to express their opinions and two or more people with different backgrounds work together to give information and participate in expressing opinions. One of the proper Socratic methods used in dental and oral health education in elementary school children is a demonstration ${ }^{16}$. In the demonstration method, educational material is presented by showing how to perform an action or procedure. Verbal illuminations, pictures, and illustrations are given. The purpose of the demonstration method is to teach a person or student how to take any action or use a new production. The advantage can be to explain a procedure visually so that it is easy to understand and students can try the knowledge it receives. The loss in this method requires tools and substantial costs and the planning takes a long time. The use of tools in changing children's behavior is very important. Educational aids are tools used by educators in delivering educational materials. This aid is more often called a teaching aid because it serves to help demonstrate something in the educational process ${ }^{17}$.

This teaching aid is organized based on the principle that the knowledge that is available to each student can be received or captured through the five senses. Aids in education have a role in enhancing learning abilities, strengthening memory, increasing interest, and facilitating appreciation. The visual aids that can be used are visual aids. The audio aids, projection props, and direct or natural props. The most effective teaching aids for education are direct teaching aids. Direct teaching aids that are considered the most effective for children are models. The model is a 
visual aid that can be seen and observed, which can be an actual tool or made to imitate the original. Students who are given education can see, feel, and examine it. Direct teaching aids help students interpret or learn an educational material so students are more likely to learn ${ }^{18}$.

The success of a health education process can be measured through several indicators such as the success of the education process in general, namely the students' knowledge of the educational material provided (knowledge). Knowledge is the result of 'knowing' and this happens after people have sensed a certain object. Behavior that is based on knowledge will be more lasting than behavior that is not based on knowledge. The second indicator is the attitude or response of students to the educational material provided (attitude). Attitude is a reaction or response of someone who is still closed to a stimulus or object. The third indicator is the practice or action taken by students in connection with educational material provided (practice) $)^{19}$.

In research on the development of diary book media for brushing teeth behavior of elementary school students, the media used is a diary. For students, school-age children are a time of full imagination, creativity, and storytelling. So it is crucial to practice story and writing skills. Given that, the diary or logbook is considered suitable to be used as an educational medium to change behavior because in the diary there is an element of excitement which is an important factor to provide student motivation. Students will record the time to brush their teeth, their duration, how to brush their teeth, and the tools and materials used in the diary to record the types, frequencies, tools used, tooth brushing techniques and their duration and location and time of the activity ${ }^{20}$.

This diary is useful for determining the area of a problem in a child's brushing behavior. Selfmonitoring can empower children to make them more aware of clean and healthy living behaviors, especially in maintaining cleanliness and caring for their dental health.

\section{Conclusion}

In the intervention group, students whose tooth brushing was in the low category decreased from $29 \%$ to $12 \%$ after being given an educational intervention using a tooth brushing diary. Whereas students whose teeth brushing was in the moderate category increased from $68 \%$ to $85 \%$ after being given an educational intervention using a tooth brushing diary media. There are differences in the actions of students who brush their teeth correctly in the group that gets the intervention and who does not get the educational intervention using the media to brush their teeth. There is a difference in the correct action of brushing teeth between students before and after getting an educational intervention using a tooth brushing diary media.

\section{Declaration}

Ethical approval: Ethical clearance was obtained from The Ministry of Health Polytechnic Semarang, Indonesia.

\section{References}

1. Endoh $M$, Takayanagi A, Fujiseki $M$, Eda $Y$, Itano $M$, Yano Y. Effects of Toothpaste Containing Granular Calcium Carbonate on Oral Health. J Int Oral Health 2019;11:249-55.

2. Mihata $\mathrm{T}$, Toda $\mathrm{S}$, Arakawa $\mathrm{H}$ The influences of dentifrice with or without foaming agents on effectiveness of mouth cleaning. A clinical trial. J Dent Health 2000;50:361-74.

3. Valkenburg C, Slot DE, Bakker EW, Van der Weijden FA Does dentifrice use help to remove plaque? A systematic review. J Clin Periodontol 2016;43:1050-8.

4. Eda $Y$, Takayanagi A, Yano Y Effects of the toothpaste containing granule-shaped cleaning agents on daily dental hygiene. J Jan Soc Dent Hygiene 2019;13:3242.

5. Tomotake $Y$, Goto $T$, Ishida $Y$, Naitou $Y$, Araki $A$, Kiyono $\mathrm{M}$, et al. An investigation of the penetration of granule components in toothpaste into peri-implant sulcus. J Jpn Soc Oral Impantology 2018;31:309-19.

6. Bosma ML, Milleman KR, Akwagyiram I, Targett D, Milleman $\mathrm{JL} A$ randomised controlled trial to evaluate the plaque removal efficacy of sodium bicarbonate dentifrices in a single brushing clinical model. BDJ Open 2018;4:17037.

7. Xue $Y, L u$, Tian $Y$, Zhou X, Cheng L, Ren B. Effect of toothpaste containing arginine on dental plaque - $A$ randomized controlled in situ study. J Dent 2017;67:88-93.

8. Almoteb MM, Alalyani SS, Gowdar IM, Penumatsa NV, Siddiqui MA, Sharanesha RB. Oral hygiene status and practices among health-care workers: A crosssectional study. J Int Oral Health 2019;11:268-73.

9. Mehta A, Kaur $G$ Oral health-related knowledge, attitude, and practices among 12-year-old schoolchildren studying in rural areas of Panchkula, India. Indian J Dent Res 2012;23:293. 
10. Gualie YT, Tayachew AT Assessment of knowledge, attitude, and practice toward oral hygiene among governmental secondary school students in Debre Tabor Town, Amhara Region, North Central Ethiopia 2018: Institutional-based cross-sectional survey. Int J Oral Health Sci 2018;8:92-8.

11. Swamy A, Sogi GM, Sudan J, Vedi A, Sharma H. Assessment of oral health status among teaching and non-teaching employees of Maharishi Markandeshwar (Deemed to be University) Mullana Ambala-A cross-sectional study. J Indian Assoc Public Health Dent 2018;16:203-7.

12. Fotedar S, Fotedar V, Bhardwaj V, Thakur AS, Vashisth $\mathrm{S}$, Thakur $\mathrm{P}$ Oral health knowledge and practices among primary healthcare workers in Shimla District, Himachal Pradesh, India. Indian J Dent Res 2018;29:858-61.

13. Desai K, Patel S Assessment of oral hygiene awareness among college students in Surat City. Nat J Community Med 2018;9:236-9.

14. Al-Mutawa SA, Shyama M, Al-Duwairi Y, Soparkar P Oral hygiene status of Kuwaiti school children. East Mediterr Health J 2011;17:387-91.

15. Adeniyi AA, Oyapero A, Ajieroh V, Sofola O, Asiyanbi $O$ Effect of health education intervention conducted by primary health care workers on oral health knowledge and practices of nursing mothers in Lagos State. J Public Health Afr 2018;9:833.

16. Aggnur M, Garg S, Veeresha K, Gambhir R Oral health status, treatment needs and knowledge, attitude and practice of health care workers of Ambala, India. Ann Med Health Sci Res 2014;4:676-81.

17. Ahmad MS, Shafie NE, Redhuan TM, Mokhtar IW. Referral pattern and treatment needs of patients managed at a Malaysian special care dentistry clinic. J Int Oral Health 2019;11:299-303.

18. Shree P, Rakshagan V, Dhanraj S, Jain A Knowledge, attitude, and practice on oral hygiene status in autistic children. Drug Invention Today 2018;10:21159.

19. Mandić J, Jovanović $S$, Mandinić $Z$, Ivanović $M$, Kosanović D, Miličić B, et al. Oral health in children with special needs. Vojnosanit Pregl 2018;75:675-81.

20. Ahmad MS, Abuzar MA, Razak IA, Rahman SA, Borromeo GL Oral health education for medical students: Malaysian and Australian students' perceptions of educational experience and needs. J Dent Educ 2017;81:1068-76. 